Research Article:

\title{
Soft Tissue Profile Changes Following Orthodontic Treatment in Patients With Unilateral Cleft Lip and Palate
}

\author{
Wisesphon Sutthidechanai ${ }^{1}$ (D), Nopawun Viriyasiri ${ }^{2}$ (D), Smorntree Viteporn ${ }^{1^{*}}$ (D)
}

1. Department of Orthodontics, Faculty of Dentistry, Chulalongkorn University, Bangkok, Thailand.

2. Craniofacial Anomalies Clinic, Faculty of Dentistry, Chulalongkorn University, Bangkok, Thailand.

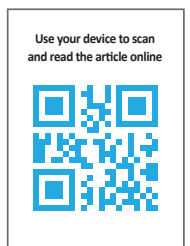

dittation: Sutthidechanai W, Viriyasiri N, Viteporn S. Soft Tissue Profile Changes Following Orthodontic Treatment in Patients With Unilateral Cleft Lip and Palate. Journal of Pediatrics Review. 2019; 7(2):121-127. http://dx.doi.org/10.32598/jpr.7.2.121

d oif: http://dx.doi.org/10.32598/jpr.7.2.121

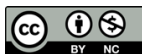

Funding: See Page 126

Article info:

Received: 22 January 2018

First Revision: 20 March 2018

Accepted: 29 April 2018

Published: 01 April 2019

Keywords:

Anterior crossbite, Class III traction, Maxillary arch expansion, Soft tissue profile, Unilateral cleft lip, Palate

\begin{abstract}
A B S T R A C T
Background: Anterior crossbite is a frequent malocclusion in patients with Unilateral Cleft Lip and Palate (UCLP). Several studies have investigated the effects of orthognathic surgery or orthopedic treatment on correction of this malocclusion. Only few studies evaluated the effect of conventional orthodontic treatment on growing patients

Objective: The present study investigated significant changes of facial profile as well as the underlying hard tissue following conventional orthodontic treatment in growing subjects with UCLP.

Methods: Lateral cephalograms of 32 non-syndromic children with UCLP (15 boys, 17 girls) with the Mean $\pm S D$ age of $10.91 \pm 2.00$ years were retrospectively collected. All patients had complete orthodontic records before and after treatments, indicating the acceptable treatment results, in respect of the degree of overbite, overjet, maximum intercuspation occlusion and facial profile. Cephalometric measurements represented dentoskeletal and soft tissue profile before and after treatments were evaluated, and significant changes were assessed by paired $t$ test. Onesample $t$ test was used to analyze significant differences between these measurements and the clinical norm.

Results: The initial characteristics of the UCLP patients were skeletal class III maxillary retrusion with relative mandibular prognathism, retroclination of the incisors, negative overjet, and increased overbite and concave facial profile. After conventional orthodontic treatment, maxillary arch expansion and class III elastic traction, the acceptable overbite and overjet were achieved by proclination of the upper incisors. Significant changes of the soft tissue profile due to facial growth and treatment included increase in facial convexity, nose length, nose depth, columellar length, soft tissue face height ratio, upper and lower lip lengths and upper lip protrusion. The soft tissue profile was acceptable after the treatment, compared to the clinical norm.
\end{abstract}

Conclusions: The early correction of the anterior crossbite with maxillary arch expansion and class III traction could improve the soft tissue facial profile of patients with UCLP.

* Corresponding Author:

Smorntree Viteporn, PhD.

Address: Department of Orthodontics, Faculty of Dentistry, Chulalongkorn University, Bangkok, Thailand.

Tel: +66 (8) 19048486

E-mail: smorntree@hotmail.com 


\section{Introduction}

left lip and or palate are the most frequent congenital anomalies of the face (1). Unilateral Cleft Lip and Palate (UCLP) is always comorbid with dentoskeletal and profile problems comprising anterior crossbite, skeletal class III maxillary retrusion and concave facial profile (2-10). Orthognathic surgery is a treatment option for adult patients. It improves the skeleton and facial profile (11-15). Early orthodontic treatment in growing subjects mainly relies on orthopedic mechanics with fixed appliance and protraction headgear (16-19), class III traction via miniplate and screws (20). A study investigated soft tissue profile changes from childhood to adulthood. However, they disregarded the treatment procedure (9).

Another study investigated the effect of orthodontic treatment in adult patients (21). This study investigated the effect of orthodontic treatment on UCLP children under the hypothesis. An acceptable occlusion and facial profile could be achieved by conventional treatment modalities comprising arch expansion and class III traction. The present study aimed to explore significant changes of dentoskeletal and facial profile following early orthodontic treatment in UCLP children and to compare the treatment results with the clinical norm groups.

\section{Methods}

The sample size was estimated by PS; Power and Sample Size Calculation Software (Vanderbilt University, Nashville, Tennessee). Mean difference of the nasolabial angle between UCLP and control groups reported by the previous studies was used for sample size calculation (9). The estimated 27 subjects were proved sufficient to achieve $80 \%$ power in detecting differences between the groups.

The sample comprised 32 non-syndromic patients with UCLP (15 boys, 17 girls), aged 7-15 years. Samples were purposively selected from the Faculty of Dentistry, Craniofacial Anomalies Clinic, Dental Hospital. All patients were presented with anterior crossbite and treated with the same treatment protocol comprising lip closure without preoperative orthopedic treatment at 3 months, palatal closure at 1-1.5 years, secondary bone grafting at the early mixed dentition stage, and orthodontic treatment with fixed appliances were performed by the same orthodontist.

Nonextraction treatment of the case included maxillary arch expansion using a quad helix before bone grafting, to correct arch constriction, followed by fixed appliance edgewise technique to correct dental crowding and anterior crossbite. Class III elastic traction initiated to obtain maximum intercuspation occlusion with acceptable overbite and overjet. The maxillary lateral incisor adjacent to the cleft site was extracted to facilitate the bone grafting procedure and complete space closure was achieved after completed orthodontic treatment in 21 of 32 cases.

All patients had complete orthodontic records before and after treatment interventions, indicating favorable treatment results with respect to degree of overbite, overjet, maximum intercuspation occlusion and facial profile. The lateral cephalograms were obtained before (T1) and after treatment (T2), under standardized conditions from the same radiographic equipment with the teeth in occlusion and the lips in relaxed position. Each radiograph was traced on an acetate paper. Also, reference points (Figure 1) were located for measuring the soft tissue profile changes (Figure 2).

\subsection{Method error study}

Pretreatment (T1) and posttreatment (T2) radiographs of 10 patients were randomly selected and retraced twice with at least 2 weeks interval, to avoid recognition of the reference points. The error of linear and angular measurements were determined by Dahlberg's formula (22).

$$
M E=\sqrt{\frac{\sum(d)^{2}}{2 n}}
$$

In this formula, $d$ is the difference between the first and second measurements (millimeters or degrees) and $\mathrm{n}$ is the number of duplicated measurements.

\subsection{Statistical analysis}

Significant changes of dentoskeletal and soft tissue profile after treatment were evaluated by the paired $t$ test. One-sample t test was used to compare the obtained results with the clinical norm groups. The significance level was set at 0.05 .

\section{Results}

The reliability of measurement was assessed. The method errors for linear and angular measurements ranged from 0.23 to $0.87 \mathrm{~mm}$ and from 0.17 to $1.84 \mathrm{de}$ grees, respectively. Shapiro-Wilk test indicated that the variables were normally distributed, thus parametric statistics were used. 


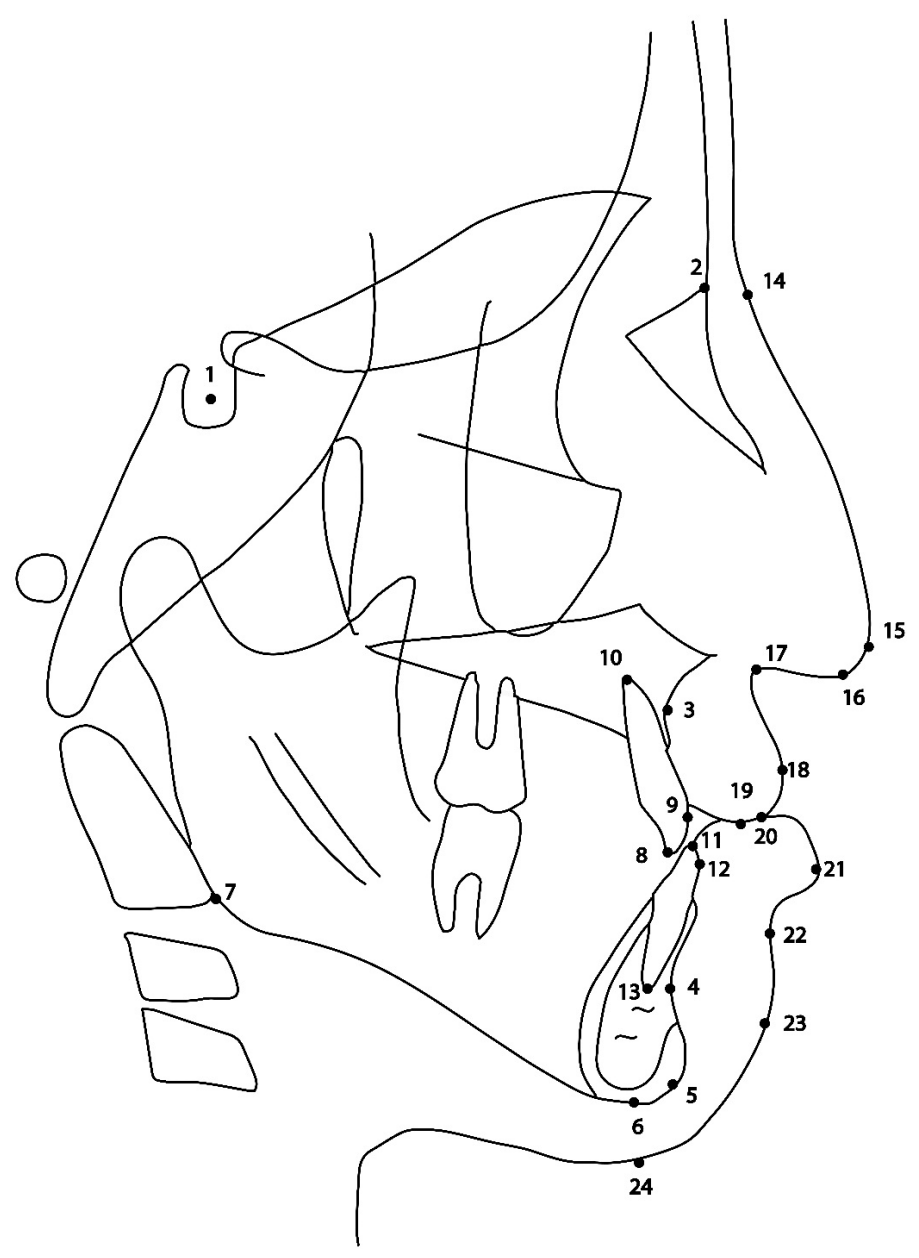

Figure 1. Cephalometric landmarks

Journal of Pediatrics Review

Abbreviations: 1. S, sella turcica; 2. N, nasion; 3. A, subspinale; 4. B, supramentale; 5. Gn, gnathion; 6. Me, menton; 7. Go, gonion; 8. Isi, maxillary central incisor edge; 9. U1, the most anterior labial point of maxillary central incisor; 10. Isa, maxillary central incisor apex; 11. lii, mandibular central incisor edge; 12. L1, the most labial point of mandibular incisor; 13. lia, mandibular central incisor apex; 14. N', soft tissue nasion; 15. Prn, pronasale; 16. Cm, columella; 17. Sn, subnasale; 18. Ls, labial superius; 19 . Sts, stomion superius; 20 . Sti, stomion inferius; 21 . Li, labial inferius; 22. Ils, inferior labial sulcus; 23. Pg', soft tissue pogonion; and 24. Me', soft tissue menton

The Mean $\pm S D$ age of the patients before and after treatments were $10.91 \pm 2.00$ and $16.19 \pm 2.47$ years, respectively. The Mean $\pm S D$ duration of treatment was $5.27 \pm 2.21$ years. At the beginning of treatment, comparison of the data with the clinical norm (Table 1), demonstrated that the patients suffered from retrusive facial pattern, skeletal class III with significant retrusion of the maxilla, retroclination of the upper and lower incisors, and negative overjet and deep overbite. There was a significant difference in the soft tissue profile of the cleft at the upper lip area. The nasolabial angle was significantly larger than the clinical norm.

After treatment (Table 1), significant changes of the dental and soft tissue profile were found at the upper incisal position and the lower lip. To obtain acceptable overjet and facial profile, the maxillary incisors had been proclined significantly resulted in increasing of the nasolabial angle until there was no significant difference with the clinical norm.

Changes of the soft tissue profile in specific areas were presented in Table 2. After treatment, soft tissue profile convexity with and without nose increased significantly (decreased $\mathrm{N}^{\prime}$ - Sn - Pg', $\mathrm{N}^{\prime}-\mathrm{Prn}-\mathrm{Pg}^{\prime}$ angles). There were significant increases of nose length ( $\mathrm{N}^{\prime}$-Prn), nose depth (Prn to $\mathrm{N}^{\prime}$-Sn), columellar length (Sn-Prn), face height ratio (Sn - Me'/ N'- Me'), lip lengths (Sn-Sts, Sti-Me') and upper protrusion (Ls to $\mathrm{Sn}-\mathrm{Pg}^{\prime}$ ).

\section{Discussion}

Correction of facial deformities and dental malocclusions of patients with UCLP is one of the most challeng- 

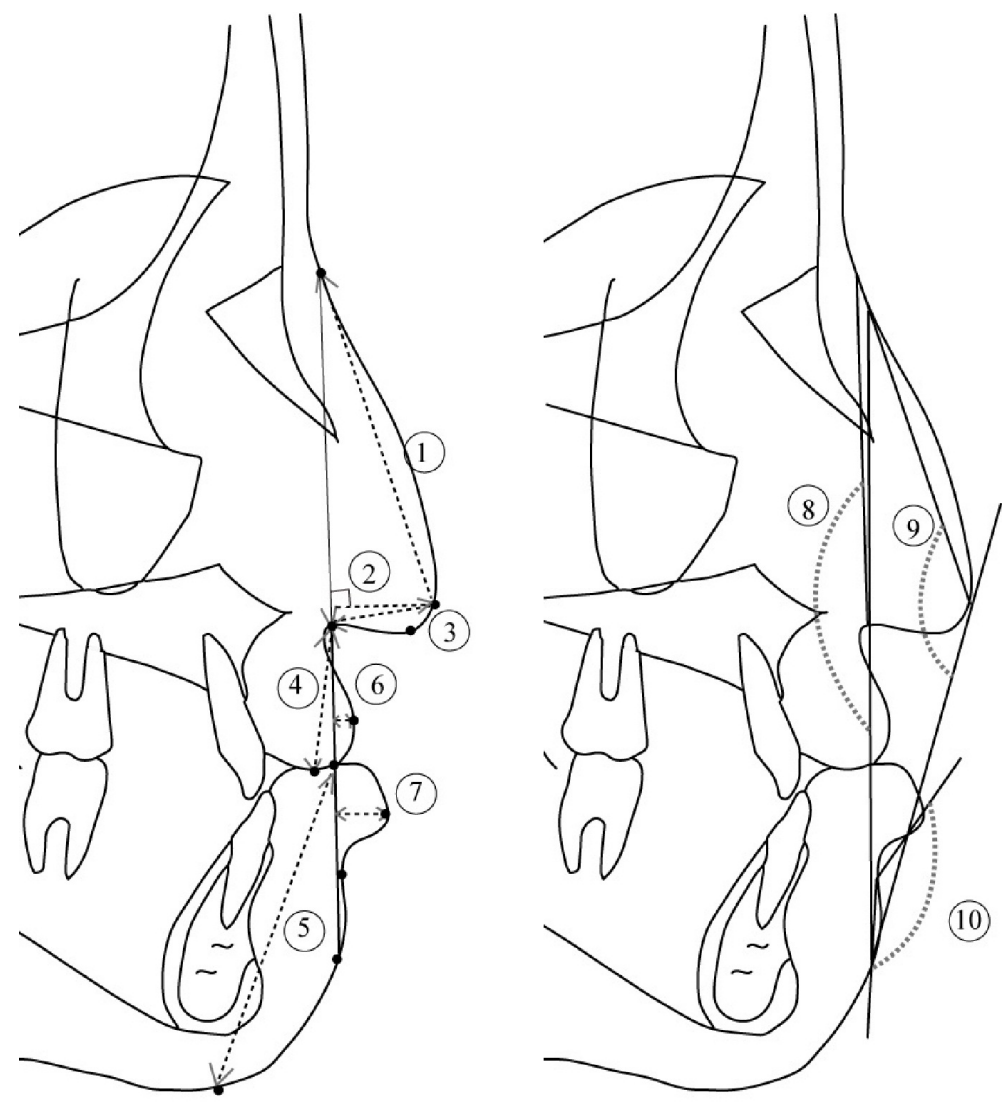

Figure 2. Cephalometric measurements utilized for evaluation of soft tissue profile changes

Abbreviations: 1. Nose length ( $N^{\prime}-$ Prn); 2. Nose depth (Prn to $N^{\prime}-S n$ ); 3. Columellar length (Sn - Prn); 4. Upper lip length (Sn - Sts); 5. Lower lip length (Sti - Me'); 6. Upper lip protrusion (Ls to $\mathrm{Sn}-\mathrm{Pg}^{\prime}$ ); 7. Lower lip protrusion (Li to $\mathrm{Sn}-\mathrm{Pg}^{\prime}$ ); 8. Soft tissue convexity without nose $\left(\mathrm{N}^{\prime}-\mathrm{Sn}-\mathrm{Pg}\right)$; 9. Soft tissue convexity with nose ( $\left.\mathrm{N}^{\prime}-\mathrm{Prn}-\mathrm{Pg}^{\prime}\right)$; and 10. Inferior labial sulcus angle (Li - lls - $\left.\mathrm{Pg}^{\prime}\right)$

ing responsibilities of orthodontists. Sufficient information about the effect of orthodontic treatment on such patients is necessary for selection of treatment modalities. The studied patients presented skeletal class III retrusive maxilla and relative mandibular prognathism, retroclined and retruded maxillary incisors that were consistent with the previous studies $(3,5)$. In cleft patients, the pressure from scar tissue of the upper lip prevents the maxillary incisors from proclination to compensate with the abnormal position of the maxilla.

After treatment, the SNA angle reduced. This effect could be explained as follows. First, the retrognathic maxilla in UCLP patients was pronounced by scar tissue after lip closure procedure (23). Second, proclination of the maxillary incisors by conventional orthodontic treatment caused a resorptive remodeling of the A point (2426). However, this treatment procedure is necessary to achieve the proper interincisal angle, as well as stability of deep bite correction $(24,25)$. In addition, this should be beneficial for improvement of the upper lip retrusion.
The study prevailed significant proclination of the upper incisors, as well as upper lip protrusion after treatment.

Class III elastic traction was among the treatment mechanics used in this study. Jinxiang et al. (26) stated that this mechanics could reduce the SNB angle, procline the upper incisors, retrocline the lower incisors and reduce the lower lip protrusion in the noncleft subjects. Our study demonstrated that the lower incisor inclination was maintained throughout treatment, the lower lip position considered from the Li to Sn-Pg', seemed stable meanwhile the distance from the lower lip to E plane reduced. This could be explained by the increased nose depth resulting in relatively reduction of the distance from the lower lip to $E$ plane.

Another reason for the low response of the lower lip to the treatment could be functional distortion comprising increased functional movements of the lower lip to assure mouth closure, swallowing and phonation as a compensation and adaptation to an impaired function of the upper lip $(5,10,27)$. These findings call for further 
Table 1. Cephalometric comparisons between before treatment ( $\mathrm{T} 1$ ), after treatment ( $\mathrm{T} 2$ ) and clinical norm

\begin{tabular}{|c|c|c|c|c|c|c|c|}
\hline \multirow{2}{*}{\multicolumn{2}{|c|}{ Cephalometric Variables }} & \multicolumn{2}{|c|}{ Mean \pm SD } & \multirow{2}{*}{$\begin{array}{c}\text { T1 vs. T2 } \\
t(P)\end{array}$} & \multirow{2}{*}{$\begin{array}{c}\text { Clinical } \\
\text { Norm } \\
\text { Mean } \pm S D\end{array}$} & \multicolumn{2}{|c|}{$t(P)$} \\
\hline & & $\mathrm{T} 1$ & T2 & & & $\begin{array}{l}\text { T1 vs. Clinical } \\
\text { Norm }\end{array}$ & $\begin{array}{l}\text { T2 vs. Clinical } \\
\text { Norm }\end{array}$ \\
\hline \multirow{5}{*}{ Skeleton } & $\operatorname{SNA}\left({ }^{\circ}\right)$ & $78.11 \pm 3.66$ & $77.81 \pm 4.24$ & $-0.69(0.50)$ & $83 \pm 4$ & $-7.56\left(0.00^{*}\right)$ & $-6.91\left(0.00^{*}\right)$ \\
\hline & $\operatorname{SNB}\left({ }^{\circ}\right)$ & $78.47 \pm 2.82$ & $78.16 \pm 3.55$ & $-0.90(0.38)$ & $79 \pm 3$ & $-1.07(0.30)$ & $-1.34(0.19)$ \\
\hline & & & & & & & \\
\hline & $\operatorname{ANB}\left({ }^{\circ}\right)$ & $-0.28 \pm 2.36$ & $-0.25 \pm 2.34$ & $0.11(0.90)$ & $4 \pm 2$ & $-10.25(0.00 *)$ & $-10.27\left(0.00^{*}\right)$ \\
\hline & SN to $\operatorname{GoGn}\left({ }^{\circ}\right)$ & $33.05 \pm 5.50$ & $33.67 \pm 7.65$ & $0.89(0.38)$ & $34 \pm 6$ & $-0.98(0.33)$ & $-0.24(0.81)$ \\
\hline \multirow{7}{*}{ Dental } & $\mathrm{U} 1$ to $\mathrm{NA}\left({ }^{\circ}\right)$ & $18.28 \pm 6.01$ & $33.55 \pm 7.10$ & $15.26\left(0.00^{*}\right)$ & $28 \pm 4$ & $-9.14(0.00 *)$ & $4.42\left(0.00^{*}\right)$ \\
\hline & $\mathrm{U} 1$ to $\mathrm{NA}(\mathrm{mm})$ & $3.17 \pm 2.13$ & $8.39 \pm 2.67$ & $12.43(0.00 *)$ & $6 \pm 2$ & $-7.52(0.00 *)$ & $5.08(0.00 *)$ \\
\hline & $\mathrm{L} 1$ to $\mathrm{NB}\left({ }^{\circ}\right)$ & $24.45 \pm 5.89$ & $24.38 \pm 5.33$ & $-0.08(0.93)$ & $32 \pm 6$ & $-7.24(0.00 *)$ & $-8.10(0.00 *)$ \\
\hline & L1 to NB(mm) & $5.64 \pm 2.19$ & $5.98 \pm 2.04$ & $1.22(0.23)$ & $6 \pm 2$ & $-0.93(0.36)$ & $-0.04(0.97)$ \\
\hline & L1 to $\mathrm{GoGn}\left({ }^{\circ}\right)$ & $92.20 \pm 6.87$ & $92.28 \pm 6.82$ & $0.08(0.94)$ & $99 \pm 4$ & $-5.60(0.00 *)$ & $-5.58(0.00 *)$ \\
\hline & Overjet(mm) & $-3.06 \pm 1.02$ & $1.78 \pm 0.94$ & $21.11\left(0.00^{*}\right)$ & $2 \pm 1$ & $-28.02\left(0.00^{*}\right)$ & $-1.32(0.20)$ \\
\hline & Overbite(mm) & $4.03 \pm 1.90$ & $1.30 \pm 0.63$ & $-7.85(0.00 *)$ & $2 \pm 1$ & $6.05(0.00 *)$ & $-6.28(0.00 *)$ \\
\hline \multirow{2}{*}{ Soft tissue } & $\begin{array}{l}\text { Lower lip to } \\
\text { E-line(mm) }\end{array}$ & $3.77 \pm 2.17$ & $2.73 \pm 2.58$ & $-2.77\left(0.01^{* *}\right)$ & $3.5 \pm 2$ & $0.69(0.49)$ & $-1.68(0.10)$ \\
\hline & Nasolabial angle $\left(^{\circ}\right)$ & $94.69 \pm 11.27$ & $92.00 \pm 9.25$ & $-1.43(0.16)$ & $90 \pm 9$ & $2.35\left(0.03^{* *}\right)$ & $1.22(0.23)$ \\
\hline
\end{tabular}

** $\mathrm{P} \leq 0.05 ; * \mathrm{P} \leq 0.01$

Journal of Pediatrics Review

Table 2. Cephalometric comparisons of soft tissue profile before treatment (T1) and after treatment (T2)

\begin{tabular}{|c|c|c|c|c|}
\hline Cephalometric Variables & $\mathrm{T} 1$ & T2 & Mean Differences & $t(P)$ \\
\hline$N^{\prime}-S n-P g^{\prime}\left({ }^{\circ}\right)$ & $176.22 \pm 6.58$ & $174.59 \pm 5.42$ & -1.63 & $-2.36\left(0.03^{*}\right)$ \\
\hline $\mathrm{N}^{\prime}-\operatorname{Prn}-\mathrm{Pg}^{\prime}\left({ }^{\circ}\right)$ & $149.69 \pm 6.65$ & $146.44 \pm 5.13$ & -3.25 & $-3.94(0.00 * *)$ \\
\hline$N^{\prime}-\operatorname{Prn}(m m)$ & $47.03 \pm 4.28$ & $51.95 \pm 3.99$ & 2.55 & $9.61\left(0.00^{* *}\right)$ \\
\hline Prn to $N^{\prime}-S n(m m)$ & $11.94 \pm 2.03$ & $14.48 \pm 2.23$ & 4.92 & $7.78\left(0.00^{* *}\right)$ \\
\hline Sn - Prn (mm) & $16.83 \pm 1.78$ & $19.13 \pm 2.27$ & 2.30 & $7.45(0.00 * *)$ \\
\hline $\mathrm{Sn}-\mathrm{Me}^{\prime} / \mathrm{N}^{\prime}-\mathrm{Me}^{\prime}$ & $0.55 \pm 0.03$ & $0.57 \pm 0.02$ & 0.01 & $2.73(0.00 * *)$ \\
\hline Sn - Sts (mm) & $19.86 \pm 3.17$ & $21.97 \pm 2.49$ & 2.11 & $7.58(0.00 * *)$ \\
\hline Sti - $\mathrm{Me}^{\prime}(\mathrm{mm})$ & $48.72 \pm 5.53$ & $53.11 \pm 4.87$ & 4.39 & $7.72(0.00 * *)$ \\
\hline Ls to $\mathrm{Sn}-\mathrm{Pg}^{\prime}(\mathrm{mm})$ & $4.02 \pm 1.25$ & $5.38 \pm 1.39$ & 1.36 & $6.52(0.00 * *)$ \\
\hline Li to $S^{\prime}-P g^{\prime}(m m)$ & $8.08 \pm 1.73$ & $7.73 \pm 1.93$ & -0.34 & $-1.05(0.30)$ \\
\hline Li - Ils $-\operatorname{Pg}^{\prime}\left({ }^{\circ}\right)$ & $133.39 \pm 11.46$ & $132.34 \pm 12.05$ & -1.04 & $-0.53(0.60)$ \\
\hline
\end{tabular}


studies on the muscular activity of the lips to clarify lip function of cleft and noncleft subjects.

The retrusive facial pattern of the cleft patients analyzed at both time points were in line with the previous studies $(6,9,28,29)$. This may be a specific characteristic of UCLP as a syndromic appearance and regardless of ethnicity. The study also indicated that the retrusive facial pattern could not be altered by conventional orthodontic treatment. Therefore, orthognathic surgery should be considered, if the treatment aims to correct the retrusive facial pattern and or lower lip protrusion.

Previous studies on growing UCLP subjects reported a progressive reduction of facial convexity $(9,29)$. Result of this study indicated that early orthodontic treatment in growing patients could contribute in the improvement of the soft tissue profile, especially the upper lip area and facial convexity. Long-term follow-up is strongly recommended for the early orthodontic treatment without orthopedic appliances, because the treatment mainly has dentoalveolar effects based on significant proclination in the upper incisors.

\section{Conclusion}

The effect of early orthodontic treatment on the correction of anterior crossbite in the growing UCLP patients was investigated. Dental compensation comprising significant proclination of the upper incisors was achieved to obtain acceptable overbite and overjet, as well as improvement of facial profile. Significant changes of the facial profile after treatment could be detected at the nasal and upper lip areas. Facial convexity and the upper lip protrusion significantly increased.

\section{Ethical Considerations}

\section{Compliance with ethical guidelines}

The current retrospective study was approved by the Human Research Ethics Committee, Faculty of Dentistry, Chulalongkorn University (HREC-DCU 2017-007), Bangkok, Thailand.

\section{Funding}

This study was supported by grants from Faculty of Dentistry, Chulalongkorn University, Bangkok, Thailand.

\section{Authors contributions}

The authors contributions is as follows: Conceptualization: Smorntree Viteporn; Methodology, Smorntree
Viteporn; Investigation: All author; Writing-origina draft: Wisesphon Sutthidechanai; Writing review \& editing: All author; Funding acquisition: Smorntree Viteporn; Resources: Smorntree Viteporn, Nopawun Viriyasiri; and Supervision: Smorntree Viteporn.

\section{Conflict of interest}

The authors declare no conflict of interest.

\section{References}

1. Fraser FC. The genetics of cleft lip and cleft palate. American Journal of Human Genetics. 1970; 22(3):336-52. [PMID] [PMCID]

2. Li Y, Shi B, Song QG, Zuo H, Zheng Q. Effects of lip repair on maxillary growth and facial soft tissue development in patients with a complete unilateral cleft of lip, alveolus and palate. Journal of Cranio-Maxillofacial Surgery. 2006; 34(6):355-61. [DOI:10.1016/j.jcms.2006.03.005] [PMID]

3. Mars $\mathrm{M}$, Houston WJ. A preliminary study of facial growth and morphology in unoperated male unilateral cleft lip and palate subjects over 13 years of age. Cleft Palate Journal. 1990; 27(1):7-10. [DOI:10.1597/15451569(1990)0272.3.CO;2] [PMID]

4. Ye B, Wu Y, Zhou Y, Jing H, Hu J, Zhang G. A comparative cephalometric study for adult operated cleft palate and unoperated cleft palate patients. Journal of Cranio-Maxillofacial Surgery. 2015; 43(7):1218-23. [DOI:10.1016/j. jcms.2015.04.015] [PMID]

5. Chaisrisookumporn N, Stella JP, Epker BN. Cephalometric profile evaluations in patients with cleft lip and palate. Oral Surgery, Oral Medicine, Oral Pathology, Oral Radiology and Endodontics. 1995; 80(2):137-44. [DOI:10.1016/ S1079-2104(05)80191-X]

6. Dogan S, Oncag G, Akin Y. Craniofacial development in children with unilateral cleft lip and palate. British Journal of Oral and Maxillofacial Surgery. 2006; 44(1):28-33 [DOI:10.1016/j.bjoms.2005.07.023] [PMID]

7. Horswell BB, Levant BA. Craniofacial growth in unilateral cleft lip and palate: Skeletal growth from eight to eighteen years. The Cleft Palate Journal. 1988; 25(2):114-21. [PMID]

8. Liu R, Lu D, Wamalwa P, Li C, Hu H, Zou S. Craniofacial morphology characteristics of operated unilateral complete cleft lip and palate patients in mixed dentition. Oral Surgery, Oral Medicine, Oral Pathology, Oral Radiology, and Endodontology. 2011; 112(6):e16-25. [DOI:10.1016/j.tripleo.2011.04.011] [PMID]

9. Moreira I, Suri S, Ross B, Tompson B, Fisher D, Lou W. Soft-tissue profile growth in patients with repaired complete unilateral cleft lip and palate: A cephalometric comparison with normal 
controls at ages 7, 11, and 18 years. American Journal of Orthodontics and Dentofacial Orthopedics. 2014; 145(3):341-58. [DOI:10.1016/j.ajodo.2013.11.018] [PMID]

10. Liu RK, Wamalwa P, Lu DW, Li CH, Hu HK, Zou S. Softtissue characteristics of operated unilateral complete cleft lip and palate patients in mixed dentition. Journal of Craniofacial Surgery. 2011; 22(4):1275-9. [DOI:10.1097/ SCS.0b013e31821c6a96] [PMID]

11. Al Waheidi EM, Harradine NW, Orth M. Soft tissue profile changes in patients with cleft lip and palate following maxillary osteotomies. The Cleft Palate-Craniofacial Journal. 1998; 35(6):535-43. [DOI:10.1597/1545-1569(1998)0352.3.CO;2] [PMID]

12. Yun YS, Uhm KI, Kim JN, Shin DH, Choi HG, Kim SH, et al. Bone and soft tissue changes after two-jaw surgery in cleft patients. Archives of Plastic Surgery. 2015; 42(4):419-23. [DOI:10.5999/ aps.2015.42.4.419] [PMID] [PMCID]

13. Heliövaara A, Hukki J, Ranta R, Rintala A. Soft tissue profile changes after Le Fort I osteotomy in UCLP patients. Journal of Cranio-Maxillo-Facial Surgery. 2000; 28(1):25-30. [DOI:10.1054/jcms.2000.0109] [PMID]

14. Susarla SM, Berli JU, Kumar A. Midfacial volumetric and upper lip soft tissue changes after Le Fort I advancement of the cleft maxilla. Journal of Oral and Maxillofacial Surgery. 2015; 73(4):708-18. [DOI:10.1016/j.joms.2014.10.033] [PMID]

15. Markose E, Paulose J, Paul ET. Soft tissue changes in cleft lip and palate patients: Anterior maxillary distraction versus conventional Le-Fort I osteotomy. Journal of Maxillofacial and Oral Surgery. 2013; 12(4):429-35. [DOI:10.1007/s12663-012-04672] [PMID] [PMCID]

16. Tindlund RS, Rygh P. Soft-tissue profile changes during widening and protraction of the maxilla in patients with cleft lip and palate compared with normal growth and development. The Cleft Palate-Craniofacial Journal. 1993; 30(5):454-68. [DOI:10.1597/1545-1569_1993_030_0454_stpcdw_2.3.co_2]

17. Tindlund RS, Rygh P. Maxillary protraction: Different effects on facial morphology in unilateral and bilateral cleft lip and palate patients. The Cleft Palate-Craniofacial Journal. 1993; 30(2):20821. [DOI:10.1597/1545-1569(1993)0302.3.CO;2] [PMID]

18. Chen KF, Lai ying So L. Sagittal skeletal and dental changes of reverse headgear treatment in Chinese boys with complete unilateral cleft lip and palate. The Angle Orthodontist. 1996; 66(5):363-72. [PMID]

19. Chen KF, Lai ying So L. Soft tissue profile changes of reverse headgear treatment in Chinese boys with complete unilateral cleft lip and palate. The Angle Orthodontist. 1997; 67(1):31-8. [PMID]

20. Yatabe M, Garib DG, de Souza Faco RA, de Clerck H, Janson G, Nguyen $\mathrm{T}$, et al. Bone-anchored maxillary protraction therapy in patients with unilateral complete cleft lip and palate: 3-dimensional assessment of maxillary effects. American Journal of Orthodontics and Dentofacial Orthopedics. 2017; 152(3):32735. [DOI:10.1016/j.ajodo.2016.12.024] [PMID] [PMCID]
21. Schultes G, Gaggl A, Kärcher H. A comparison of growth impairment and orthodontic results in adult patients with clefts of palate and unilateral clefts of lip, palate and alveolus. British Journal of Oral and Maxillofacial Surgery. 2000; 38(1):26-32. [DOI:10.1054/bjom.1999.0132] [PMID]

22. Houston WJ. The analysis of errors in orthodontic measurements. American journal of orthodontics. 1983; 83(5):382-90. [DOI:10.1016/0002-9416(83)90322-6]

23. Naqvi ZA, Shivalinga BM, Ravi S, Munawwar SS. Effect of cleft lip palate repair on craniofacial growth. Journal of Orthodontic Science. 2015; 4(3):59-64. [DOI:10.4103/2278-0203.160236] [PMID] [PMCID]

24. Al-Abdwani R, Moles DR, Noar JH. Change of incisor inclination effects on points A and B. The Angle Orthodontist. 2009; 79(2):462-7. [DOI:10.2319/041708-218.1]

25. Al Nimri KS, Hazza’a AM, Al Omari RM. Maxillary incisor proclination effect on the position of point $A$ in Class II division 2 malocclusion. The Angle Orthodontist. 2009; 79(5):880-4. [DOI:10.2319/082408-447.1] [PMID]

26. Chen $Q$, Zhang $C$, Zhou Y. The effects of incisor inclination changes on the position of point A in Class II division 2 malocclusion using three-dimensional evaluation: A long-term prospective study. International Journal of Clinical and Experimental Medicine. 2014; 7(10):3454-60. [PMID] [PMCID]

27. Berg R. Stability of deep overbite correction. The European Journal of Orthodontics. 1983; 5(1):75-83. [DOI:10.1093/ejo/5.1.75] [PMID]

28. Ludwig M. A cephalometric analysis of the relationship between facial pattern, interincisal angulation and anterior overbite changes. The Angle Orthodontist. 1967; 37(3):194-204. [PMID]

29. Jiuxiang L, Jinfuang $H$, Xiangleng $Z$. A cephalometric evaluation of hard and soft tissue changes during Class III traction. The European Journal of Orthodontics. 1985; 7(3):201-4. [DOI:10.1093/ejo/7.3.201]

30. Ufuk Toygar T, Okan Akçam M, Arman A. A cephalometric evaluation of lower lip in patients with unilateral cleft lip and palate. The Cleft Palate-Craniofacial Journal. 2004; 41(5):485-9. [DOI:10.1597/03-115.1] [PMID]

31. Nollet PJ, Katsaros C, Huyskens RW, Borstlap WA, Bronkhorst EM, Kuijpers Jagtman AM. Cephalometric evaluation of longterm craniofacial development in unilateral cleft lip and palate patients treated with delayed hard palate closure. International Journal of Oral and Maxillofacial Surgery. 2008; 37(2):12330. [DOI:10.1016/j.ijom.2007.09.168] [PMID]

32. Sadowsky C, Aduss H, Pruzansky S. The soft tissue profile in unilateral clefts. The Angle Orthodontist. 1973; 43(3):233-46. [PMID] 